\title{
Prevalence of Prediabetes and its Risk Factors among the Employees of Ambo University, Oromia Region, Ethiopia
}

\author{
Rajamanickam Vinodhini $^{1^{*}, \text { Legesse Kebede }^{2}, \text { Girma Teka }^{3} \text {, Bersisa Asana }}{ }^{4}$, Tesfaye Abel ${ }^{5}$ \\ ${ }^{1}$ Unit of Biochemistry, Department of Medicine, College of Medicine and Health Sciences, Ambo University, Ambo Town, Ethiopia. \\ ${ }^{2}$ Department of Internal Medicine, Ambo University Referral Hospital, Ambo Town, Ethiopia. \\ ${ }^{3}$ Department of Public Health, College of Medicine and Health Sciences, Ambo University, Ambo Town, Ethiopia. \\ ${ }^{4}$ Department of Surgery, Ambo University Referral Hospital, Ambo Town, Ethiopia. \\ ${ }^{5}$ Department of Surgery, Aka-Kotebe General Hospital, Addis Ababa, Ethiopia.
}

Received: 2 Aug 2017

Revised : 5 Sep 2017

Accepted: 22 Sep 2017

Corresponding Author: Rajamanickam Vinodhini Unit of Biochemistry, Department of Medicine, College of Medicine and Health Sciences, Ambo University, Ambo Town, Ethiopia.

Phone: +251911895220

E-mail: sivaniswetha@yahoo.com

\begin{abstract}
Background: Prediabetes is a metabolic condition which is characterized by the presence of higher levels of blood glucose. It can be treated by lowering high blood glucose level and maintaining the healthy lifestyle habits, healthy meal plan and regular exercise. The aim of this study was to evaluate the prevalence of prediabetes and to identify the risk factors involved in its progression.

Materials and Methods: A cross-sectional study design was adapted for the present research work. The targeted participants were adults under the age group of 35-59 years. This research included all voluntary individuals who were screened according to the guidelines of the centers for disease control and prevention (CDC). This study protocol included self-administered questionnaires; anthropometric data and blood biochemistry. A total of 380 respondents arrived at the baseline sample in which 16 subjects who had diabetes were excluded and the remaining 364 samples with normal glucose tolerance (NGT), impaired fasting glucose (IFG) and impaired glucose tolerance (IGT) were included as the study subjects. All statistical analysis was carried out by IBM SPSS statistics 20.0 software. The recorded $p$ values are on the basis of two-sided tests with a statistical significance of $\mathrm{p} \leq 0.05$.

Results: The present study showed the higher prevalence of prediabetes with normal glucose tolerance, impaired fasting glucose and/or impaired glucose tolerance (IGT) as $79.7 \%, 8.0 \%, 6.8 \%$ and $5.5 \%$ respectively. The total estimated prevalence of prediabetes was $20.3 \%$ which includes $12.6 \%$ of males and $28.2 \%$ of females. As per WHO guidelines $23.0 \%$ of pre-obese and $34.4 \%$ of obese in the target groups whose BMI $\geq 25$ with their risk estimate of $2.28(0.8-6.5)$ for males and $2.25(1.03-4.9)$ for females are in the prediabetic groups. According to the seventh report of joint national committee (JNC) standards around $20.3 \%$ of hypertensive individuals with OR: $0.5(0.21-1.3)$ for males and OR: $0.12(0.1-$ 0.30 ) for females were in prediabetes. Sex, age, occupation, income, alcohol drinking, and elevation in modified risk factors including body mass index (BMI), waist to hip ratio (WHR), blood pressure (BP), high-density lipoprotein cholesterol (HDL) and low-density lipoprotein cholesterol (LDL) were significantly associated with prediabetes.

Conclusion: The present study indicated a higher prevalence of prediabetes and the effect of possible risk factors in the target population. Hence self-care should be prioritized in the community to maintain the normal BP, blood glucose, BMI and regular physical exercise. It is highly recommended to conduct various intervention programs in the form of counseling and health education after the clients are successively screened for prediabetes. This strategy helps in the management of prediabetes and controls a huge number of people from the risk of T2DM.
\end{abstract}

Keywords: Oral glucose tolerance test; Prevalence; Prediabetes; Risk factors Factors among the Employees of Ambo University, Oromia Region, Ethiopia. Res Mol Med, 2017; 5(3): 11-20 


\section{Introduction}

Diabetes mellitus (DM) is the most common endocrine disorder which currently affects more than 100 million people in the world. The number of newly diagnosed DM cases is increasing due to aging, increasing the prevalence of obesity and physical inactivity (1). There are several types of diabetes in which type-2 diabetes mellitus (T2DM) is the most prevalent form which sequentially alters the dysregulation in glucose, blood pressure, body mass index and lipid metabolism (2-4). The development of T2DM begins over a long period of time. Before its progression, a transient stage is developed in which individuals suffer from impaired fasting glucose (IFG), impaired glucose tolerance (IGT) or combined IFG/IGT but not high to be diagnosed with diabetes, a condition which is known as prediabetes. ADA stated this condition as intermediate hyperglycemia formed between normal glucose tolerance and T2DM (5). Around 5-10\% of people with prediabetes become diabetic every year because of asymptomatic state and the conversion rate varies by population characteristics and the definition of prediabetes $(6,7)$. The majority of peoples are unaware of this condition and are often diagnosed after experiencing complications including retinopathy and other cardiovascular diseases (CVD). The latest estimates of the prevalence of DM and prediabetes in Africa are about 3.2\% and $7.9 \%$ (8). The estimated prevalence of prediabetes will be doubled by the year $2040(9,10)$. In diabetes, risk prediction variables including age, sex, lifestyle information, BMI, and blood glucose measurement provide first line data to reinforce the risk estimation. This system is applicable and supportive for risk estimation of diabetes in the developing countries where resources and skilled manpower are limited and scarce. In case of more precise risk estimation incorporation of $2 \mathrm{hrs}$ postprandial glucose (2hPGL) load into a model that already included fasting plasma glucose (FPG) can improve the prediction $(11,12)$. HbA1c (Glycosylated haemoglobin) is a sensitive indicator and a valid predictor of diabetes including undiagnosed cases, but it should not be used to identify prediabetes (13). It is difficult to identify universal cut-off points for $\mathrm{HbA1c}$ in different ethnic groups, with higher levels are observed among people of African origin $(14,15)$.

The risk of developing T2DM can be delayed or reduced by adopting a healthy lifestyle, reducing obesity, healthy eating habits and increasing physical activity. Several clinical intervention programs have reported reductions in the risk of diabetes development in prediabetic individuals after lifestyle and drug-based interventions (16-18).

So there is an urgent need to evaluate the risk factors and their association in the progression of prediabetes in the adult population. In Ethiopia, the number of diabetic cases estimated by WHO increased to 1.8 million by the year 2030 (19). The prevalence of undiagnosed T2DM in East Shoa was reported as 5\% (20). Globalization, rapid adaptation to western lifestyle, unhealthy eating habits like skipping the breakfast (or) eating junk foods because of financial hardships, job stress, lack of awareness, limitation in screening protocols, less propaganda for intervention programs and poor accessibility to health care services are some of the possible determinants of prediabetes in the low and middle income countries (LMICs). So we sought to assess the prevalence and the association of combined risk factors in the progression of prediabetes. This study was performed since the diabetic population is more in the community but there is no static record about prediabetes. So we aimed to evaluate the baseline information on the prevalence of prediabetes in the adult population working in Ambo University, Oromia Region, Ethiopia.

\section{Materials and methods}

Participants and study pattern

A cross-sectional study was carried out from $6^{\text {th }}$ February to $25^{\text {th }}$ June 2016 in the adult population working at Ambo University. It is one of the fastest growing Ethiopian Universities, currently expanding with four campuses. The objectives and benefits of the screening process were communicated to all institutes and schools in the form of notice, poster, and advertisement. The sample size was calculated by using the formula represented for finite population (21) with $95 \%$ confidence interval and $50 \%$ of prevalence for prediabetes. All volunteers who are aged $\geq 35$ years are recruited by the General Practitioner (GP) team for an opportunistic screening and to identify the risk group for prediabetes. The study was conducted after approval of Ethical clearance received from an institutional review committee of Ambo University (Ref. No: RKTTCMHS-73 dated on 16/01/2016). We informed the objectives of the study, and a written consent was obtained from every subject before physical examination, questionnaire administration, and blood sample collection. The baseline information including demographic characteristics, lifestyle factors, knowledge, self-care, dietary habits and physical activity $(22,23)$ were collected using the standard self-reported questionnaire printed in Amharic (National language) and English version.

\section{Anthropometrics and blood pressure}

Weight and height were measured to the nearest 0.1 $\mathrm{Kg}$ and $0.1 \mathrm{~cm}$ using a portable standard weight and 
height scale. The subjects were instructed to stand barefoot with their head in an upright position. The body mass index (BMI) was determined by dividing the weight (in kilograms) by the height (in meters) square. The individuals were classified on the basis of their BMI as Underweight $(<18.5)$, Normal weight (18.5-24.9), Pre-obese (25.0-29.9) and Obese ( $\geq 30)$ (24). Waist Circumference (WC) was measured by placing a specially designed spring-loaded tape device (Fazzini tapes, Italy) around the abdomen (ensuring that the tape measure is horizontal). It should be comfortable and not cause compression of the skin. The participants were classified according to the WHO cut-off points for the risk of metabolic complications (Males $>94 \mathrm{~cm}$ ) and (females $>80 \mathrm{~cm}$ ) (25). Hip circumference was measured at the widest part of the hip at the level of the greater trochanter to the nearest half-centimeter. The waist to hip ratio (WHR) was calculated by the ratio of waist circumference $(\mathrm{cm})$ to the hip circumference $(\mathrm{cm})$. The participants were in the risk if the WHR value for males was $\geq 0.90 \mathrm{~cm}$ and females were $\geq 0.85 \mathrm{~cm}$. Waist to height ratio (WHtR) was calculated by the ratio of waist circumference $(\mathrm{cm})$ to the height $(\mathrm{cm})$ (26). Each measurement was repeated twice and in case of discrepancy, it was repeated for the third time to ensure the accuracy. The blood pressure was measured using a digital blood pressure machine and a manual mercury sphygmomanometer. At least three readings at 5-minute intervals, as per JNC VII criteria were used for the systolic blood pressure (SBP) and diastolic blood pressure (DBP) (27).

\section{Biochemical measurements}

Under strict aseptic precautions, $5 \mathrm{ml}$ of venous blood samples were collected from an antecubital vein of the selected subjects after overnight fasting (8hrs) and stored in appropriate serum separating tubes (SST, BD vacutainer). The samples were centrifuged and the serum was separated for the determination of lipid profileincluding totalcholesterol (TC), triacylglycerol (TAG), high density lipoprotein cholesterol (HDL-C) and low density lipoprotein cholesterol (LDL-C) using automatic standard routine enzymatic method and commercial kits (Linear type Reagent BA-88A, Barcelona, Spain) in clinical chemistry analyzers (Humastar 80, Germany and Echo Autoanalyzer, Italy). According to the national cholesterol education program criteria, the fasting triacylglycerol > $150 \mathrm{mg} / \mathrm{dl}(1.7 \mathrm{mmol} / \mathrm{l})$, HDL-C cholesterol $<40 \mathrm{mg} / \mathrm{dl}(1.0 \mathrm{mmol} / \mathrm{l})$ in men and $<50$ $\mathrm{mg} / \mathrm{dl}(1.3 \mathrm{mmol} / \mathrm{l})$ in women and LDL-C $>160$ are considered as risk (28). In oral glucose tolerance test (OGTT), the blood glucose was measured in a fasting state (at least $8 \mathrm{hr}$ ) by finger prick using a disposable sterile lancet (100 ct $26 \mathrm{G}$ needle) and the fasting plasma glucose values were recorded using Prodigy autocode one touch glucometer. The participants whose IFG value $\geq 100$ were allowed to drink $75 \mathrm{~g}$ of standard glucose for oral glucose tolerance test and the results were recorded after $2 \mathrm{hrs}$ post glucose load (29).

\section{Definition for prediabetes}

The prevalence of prediabetes was determined as an independent variable when all the study subjects were within the range of IFG from $100 \mathrm{mg} / \mathrm{dL}(5.6 \mathrm{mmol} / \mathrm{L})$ to $125 \mathrm{mg} / \mathrm{dL}(6.9 \mathrm{mmol} / \mathrm{L})$ and/or IGT from 140 $\mathrm{mg} / \mathrm{dL}(7.8 \mathrm{mmol} / \mathrm{L})$ to $199 \mathrm{mg} / \mathrm{dL}(11.0 \mathrm{mmol} / \mathrm{L})$. These two categories are considered as a high-risk state for the progression of diabetes $(30,31)$.

\section{Exclusion criteria}

Exclusion criteria for in the present investigation included pregnant women, known diabetes confirmed by a physician (32), the FPG $\geq 126 \mathrm{mg} / \mathrm{dL}(7.0$ $\mathrm{mmol} / \mathrm{L})$ and $2 \mathrm{hrs} P G \geq 200 \mathrm{mg} / \mathrm{dL}(11.1 \mathrm{mmol} / \mathrm{L})$ during the OGTT testing and subjects using any sort of antidiabetic medication. A total of 378 respondents arrived at the baseline sample in which 16 subjects who had diabetes were excluded and the remaining 364 samples with normal glucose tolerance (NGT), impaired fasting glucose (IFG) and impaired glucose tolerance (IGT) were included as the study subjects with the sex ratio of $183(50.3 \%)$ males and 181 (49.7) females.

\section{Statistical methods}

The prevalence of prediabetes was expressed in percentage. The sex-wise comparison of all independent variables was done by t-test and the values are expressed as a mean and standard deviation. The odds ratio (OR) of the male and female risk factors was calculated using $95 \%$ CI with lower and upper bound values and Pearson chi-square test. To identify the correlates of the dependent variable, all categorical variables were included in a step-wise, logistic regression model to study their independent prognostic significance and its correlation with Pre-DM. All statistical analysis was carried out by IBM SPSS statistics 20.0 software. The recorded $\mathrm{p}$ values are on the basis of two-sided tests with a cut-off for statistical significance of $\mathrm{p} \leq 0.05$.

\section{Results}

The present study was conducted to estimate the prevalence of prediabetics in the target population and to identify the significance of associated risk factors in the progression of prediabetes. Table 1 showed the baseline information including education, marital status, occupation, income, knowledge and self-care in the target population and the data are presented in percentage. 
Table 1. Baseline characteristics of the adult sample population aged above $\geq 35$ years.

\begin{tabular}{|c|c|c|c|}
\hline Variables & $\begin{array}{l}\text { Males } \\
\text { N \% }\end{array}$ & $\begin{array}{l}\text { Females } \\
\text { N \% }\end{array}$ & $\begin{array}{l}\text { Total } \\
\text { N \% }\end{array}$ \\
\hline \multicolumn{4}{|l|}{ Education } \\
\hline Technical diploma & $3(0.8)$ & $9(2.5)$ & $12(3.3)$ \\
\hline Grade 12 & $31(8.5)$ & $34(9.3)$ & 65 (17.9) \\
\hline $\mathrm{BSc}$ & $76(20.9)$ & $62(17.0)$ & $138(37.9)$ \\
\hline MSc and above & $87(23.9)$ & $62(17)$ & 149 (40.9) \\
\hline \multicolumn{4}{|l|}{ Marital status } \\
\hline Unmarried & $25(6.9)$ & $27(7.4)$ & $52(14.3)$ \\
\hline Married & $131(36.0)$ & $119(32.7)$ & $250(68.7)$ \\
\hline Separated/Divorced & $27(7.4)$ & $35(9.6)$ & $62(17.0)$ \\
\hline \multicolumn{4}{|l|}{ Occupation status } \\
\hline Academic instructor & $69(19.0)$ & $24(6.6)$ & $93(25.6)$ \\
\hline Skilled worker & $44(12.1)$ & $41(11.3)$ & $85(23.4)$ \\
\hline Office personal & $38(10.4)$ & $44(12.1)$ & $82(22.5)$ \\
\hline Administration & $51(14.0)$ & $53(14.6)$ & 104 (28.6) \\
\hline \multicolumn{4}{|l|}{ Income } \\
\hline Low & $93(25.6)$ & $110(30.2)$ & $203(55.8)$ \\
\hline Medium & $64(17.6)$ & 49 (13.5) & $113(31.0)$ \\
\hline High & $26(7.1)$ & $22(6.0)$ & $48(13.2)$ \\
\hline \multicolumn{4}{|l|}{ Knowledge } \\
\hline Poor & 97 (26.6) & $87(23.9)$ & $184(50.5)$ \\
\hline Fair & $62(17)$ & $70(19.2)$ & $132(36.3)$ \\
\hline Good & $29(8.0)$ & $19(5.2)$ & $48(13.2)$ \\
\hline \multicolumn{4}{|l|}{ Self-Care } \\
\hline Disagree & $26(7.2)$ & $19(5.2)$ & $45(12.4)$ \\
\hline Neutral & $38(10.1)$ & $55(15.1)$ & $93(25.5)$ \\
\hline Agree & $119(32.7)$ & $107(29.4)$ & $226(62.1)$ \\
\hline
\end{tabular}

Note: $\mathrm{N}$ is the number of respondents.

Background information

The study participants include $50.3 \%$ males and $49.7 \%$ females with the mean age of $45.9 \pm 5.1$. The average work experience of the target group is $16 . \pm$ 11.7 with $69.5 \%$ having more than 10 years of experience at Ambo University. Among the participants $25.6 \%$ are academic instructors, $23.4 \%$ are skilled workers, $22.5 \%$ are office personnel and $28.6 \%$ are administrative workers with their educational background as $3.3 \%$ with a technical diploma, $17.9 \%$ had completed grade twelve, $37.9 \%$ are B.Sc. holders and $40.9 \%$ have completed M.Sc. and above. In the target population, $14.30 \%$ ware unmarried, $68.70 \%$ were married and $17 \%$ were 
separated or divorced. Socioeconomic status of the individuals includes $55.8 \%$ in low, $31.0 \%$ in medium and $13.2 \%$ are in high-income groups. About the level of knowledge on prediabetes, nearly $50.5 \%$ have poor, $36.3 \%$ have fair and $13.2 \%$ have good knowledge and the self-care of the respondents are signified as $12.4 \%$ disagreed, $25.5 \%$ neutral and $62.1 \%$ are in good agreement in the target population. After excluding the known 16 diabetic samples, a total of 364 samples arrived, within which 74 are prediabetic population $(19.5 \%)$. The estimated prevalence of the sample population of 364 is $20.3 \%$.

Table 2. Descriptive statistics of each test variable in the study population.

\begin{tabular}{|c|c|c|c|c|c|c|}
\hline \multicolumn{7}{|c|}{ t-test } \\
\hline Variables & $\begin{array}{l}\text { Males }(\mathrm{N}=183) \\
(50.3 \%)\end{array}$ & $\begin{array}{l}\text { Females }(\mathrm{N}=181) \\
(49.7 \%)\end{array}$ & $\begin{array}{l}\text { Mean } \\
\text { Difference }\end{array}$ & $95 \%$ & CI & P-Value \\
\hline Age & $46.4 \pm 5.4$ & $45.4 \pm 4.8$ & 1.05 & -0.01 & 2.1 & 0.05 \\
\hline Education & $3.1 \pm 0.9$ & $3.2 \pm 0.9$ & -0.1 & -0.25 & 0.1 & 0.46 \\
\hline Marital status & $2.06 \pm 0.6$ & $2.10 \pm 0.7$ & -0.05 & -0.19 & 0.1 & 0.53 \\
\hline Occupation & $2.2 \pm 1.2$ & $2.6 \pm 1.2$ & -0.41 & -0.66 & 0.2 & 0.002 \\
\hline Income & $1.5 \pm 0.7$ & $1.6 \pm 0.7$ & -0.13 & -0.28 & 0.01 & 0.08 \\
\hline Knowledge & $0.6 \pm 0.5$ & $0.45 \pm 0.5$ & 0.11 & 0.001 & 0.21 & 0.05 \\
\hline Self-care & $0.89 \pm 0.3$ & $0.70 \pm 0.5$ & 0.19 & -0.27 & 1.1 & 0.001 \\
\hline Drinking alcohol & $0.56 \pm 0.5$ & $0.53 \pm 0.5$ & 0.02 & -0.1 & 0.07 & 0.60 \\
\hline Unhealthy eating habits & $0.40 \pm 0.5$ & $0.48 \pm 0.5$ & -0.08 & -0.03 & 0.2 & 0.10 \\
\hline Physical inactivity & $0.39 \pm 0.5$ & $0.45 \pm 0.5$ & -0.06 & -0.02 & 0.1 & 0.40 \\
\hline BMI & $26.2 \pm 2.6$ & $26.1 \pm 2.9$ & 0.2 & -0.4 & 0.7 & 0.60 \\
\hline WC & $90.8 \pm 6.4$ & $81.8 \pm 3.2$ & 8.9 & 8.0 & 10.0 & 0.001 \\
\hline WHR & $0.95 \pm 0.1$ & $0.87 \pm 0.04$ & 0.1 & 0.07, & 0.1 & 0.000 \\
\hline WHtR & $0.47 \pm 0.04$ & $0.49 \pm 0.04$ & -0.01 & -0.02 & -0.005 & 0.002 \\
\hline SBP & $129.4 \pm 12.4$ & $124.8 \pm 11.1$ & 4.52 & 2.1 & 6.95 & 0.001 \\
\hline DBP & $84.6 \pm 7.1$ & $81.8 \pm 5.3$ & 2.8 & 1.5 & 4.04 & 0.001 \\
\hline Total Cholesterol & $201.2 \pm 14.4$ & $204.4 \pm 15.2$ & -3.2 & -6.3 & 1.5 & 0.04 \\
\hline TAG's & $151.7 \pm 6.9$ & $156.1 \pm 8.4$ & -4.4 & -5.9 & 2.8 & 0.001 \\
\hline $\mathrm{HDL}-\mathrm{C}$ & $43.6 \pm 7.5$ & $52.4 \pm 9.8$ & -8.8 & -10.6 & -7.1 & 0.001 \\
\hline $\mathrm{LDL}-\mathrm{C}$ & $150.3 \pm 20.9$ & $153.0 \pm 18.6$ & -2.7 & -6.7 & 1.4 & 0.20 \\
\hline IFG & $90.1 \pm 9.8$ & $93.9 \pm 11.6$ & -3.8 & -5.9 & -1.5 & 0.001 \\
\hline IGT & $126.1 \pm 18.7$ & $132.4 \pm 19.6$ & -6.4 & -10.3 & 2.4 & 0.002 \\
\hline
\end{tabular}

P- Value refers to the analysis of the difference in mean of each variable in male and female.

The descriptive statistics and mean difference of all variables including age, education, marital status, occupation, income, knowledge, self-care, drinking alcohol, unhealthy eating habits, physical inactivity,
BMI, WC, WHR, WHtR, SBP, DBP, total cholesterol, TAG's, HDL-C, LDL-C, IFG and IGT in male and female respondents are presented in the Table 2. 
The prevalence of associated risk factors and the possible risk estimates in the target groups are presented in Table 3.

\section{Prevalence of risk factors}

The age group distribution of prediabetes in the selected study population is illustrated in Figure 1. The prevalence of prediabetes comprises $12.6 \%$ of males and $28.2 \%$ of females with a total prevalence of $20.3 \%$. The estimated total prevalence is $20.3 \%$ which comprises $12.6 \%$ of males and $28.2 \%$ of females. Increase in age is one of the known risk factors. $8.6 \%$ of pre-diabetic prevalence was observed in the age group of 35-39 with OR: 0.39 (0.03-4.7), $20.8 \%$ in $40-44$ aged participants with OR: 3.4 (1.3-9.2), $22 \%$ with OR: $2.9(1.2-7.4)$ in the target groups at the age range of $45-49,21.7 \%$ in the respondents of 50-54 age group with OR: 3.1 (0.9$10.5)$ and $23.5 \%$ of prevalence in the age group of 55-59 with OR: $5.5(0.5-65.2)$ and the overall significance in all age groups was $\mathrm{p}<0.002$.

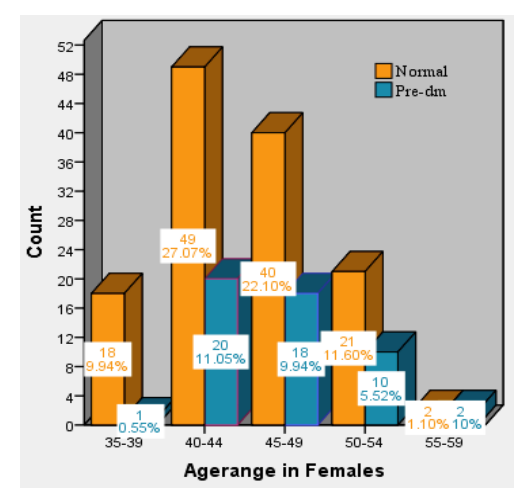

Figure 1. Age group distribution of prediabetes in the study population $(\mathrm{N}=364)$.

About the lifestyle factors $25.3 \%$ of respondents who drink alcohol with OR: 0.68 (0.4-1.3) for males and $0.34(0.1-0.9)$ for females, around $18.2 \%$ of the population who had no healthy eating habits with OR: 1.1: (0.5-2.0) for males and OR: $2.79(1.1-7.2)$ for females and $17.8 \%$ of respondents who had physical inactivity with OR: $0.87(0.5-1.7)$ for males and OR: 3.38 (1.4-8.5) for females are in the prediabetes population.

Table 3. Prevalence of pre-diabetic risk factors and its risk estimate values in the target groups.

\begin{tabular}{|c|c|c|c|c|}
\hline \multirow{2}{*}{ Variables (Risk factors) } & \multicolumn{2}{|c|}{ Risk estimate (95\% CI) } & \multirow{2}{*}{$\begin{array}{l}\text { Total } \\
\chi 2 \\
(d f=1)\end{array}$} & \multirow{2}{*}{ P-Value } \\
\hline & Males & Females & & \\
\hline Drinking alcohol & $0.68(0.4-1.3)$ & $0.34(0.13-0.9)$ & 4.657 & $0.01 *$ \\
\hline Unhealthy eating habits & $1.1(0.5-2.0)$ & $2.79(1.1-7.2)$ & 1.253 & $0.05 *$ \\
\hline Physical inactivity & $0.87(0.5-1.7)$ & $3.38(14-8.5)$ & 1.964 & $0.04 *$ \\
\hline Elevated $\mathrm{BMI} \geq 25$ and above & $2.28(0.8-6.5)$ & $2.25(1.03-4.9)$ & 7.590 & $0.002 * *$ \\
\hline $\begin{array}{l}\text { Elevated WC }>94 \mathrm{~cm} \text { for men and }>80 \mathrm{~cm} \text { for } \\
\text { women }\end{array}$ & $1.2(0.6-2.8)$ & $2.5(0.9-6.7)$ & 5.652 & $0.006^{* *} *$ \\
\hline $\begin{array}{l}\text { Elevated WHR, } \geq 90 \mathrm{~cm} \text { for men) and } \geq 85 \mathrm{~cm} \\
\text { for women }\end{array}$ & $1.97(0.8-4.9)$ & $1.96(0.76-5.1)$ & 9.183 & $0.001 * *$ \\
\hline $\begin{array}{l}\text { At risk WHtR } 0.46-0.54 \text { for men and } 0.45 \text { - } \\
0.53 \text { for women }\end{array}$ & $1.9(0.78-4.7)$ & $1.4(0.61-3.2)$ & 6.747 & $0.003 * *$ \\
\hline Elevated $\mathrm{BP} \geq 130 \mathrm{SBP}$ and $\geq 85 \mathrm{DBP}$ & $0.5(0.21-1.3)$ & $0.12(0.1-0.30)$ & 27.671 & $0.001 * *$ \\
\hline $\begin{array}{l}\text { Elevated Free cholesterol > } 200 \text { at border line } \\
\text { high risk }\end{array}$ & $1.6(0.8-3.1)$ & $3.09(1.0-9.5)$ & 4.455 & $0.01 *$ \\
\hline Elevated $\mathrm{TAG}$ 's $\geq 150$ at risk & $1.8(0.69-4.9)$ & $1.55(0.75-3.2)$ & 3.472 & $0.02 *$ \\
\hline Elevated $\mathrm{LDL}-\mathrm{C} \geq 160$ at risk & $1.6(0.8-3.2)$ & $3.3(1.1-10.0)$ & 5.131 & $0.008 * *$ \\
\hline $\begin{array}{l}\text { Reduced } \mathrm{HDL}-\mathrm{C}<40 \text { for men and }<50 \text { for } \\
\text { women at risk }\end{array}$ & $0.3(0.11-0.71)$ & $1.0(0.50-1.9)$ & 2.457 & $0.03 *$ \\
\hline
\end{tabular}

$\mathrm{P}$ - Value refers to the analysis of each risk factor in males and females (**highly significant, *significant). 
As per WHO guidelines $23.0 \%$ of pre-obese and $34.4 \%$ of obese in the target groups whose BMI $\geq 25$ with their risk estimate of 2.28 (0.8-6.5) for males and $2.25(1.03-4.9)$ for females are in the prediabetic groups, $23.9 \%$ of respondents with abdominal obesity (elevated WC) including OR: $1.2(0.6-2.8)$ for males and OR: $2.5(0.9-6.7)$ for females were in the prevalence of prediabetes. $24.9 \%$ of target groups with elevated WHR with OR: $1.97(0.8-4.9)$ for males and females OR: $1.96(0.76-5.1)$ and $24.6 \%$ of population who are at risk for WHtR with OR: 1.9(0.78-4.7) for males and females OR: 1.4 (0.613.2) are included in the prevalence of prediabetic groups. According to the seventh report of JNC standards around $20.3 \%$ of hypertensive individuals with OR: 0.5 (0.21-1.3) for males and OR: $0.12(0.1-$ $0.30)$ for females were in prediabetes. In lipid profile, as per the national cholesterol education program (NCEP) -Adult treatment panel (ATP III) guidelines, nearly $23.8 \%$ of population is in high cholesterol with risk estimate for males as $1.6(0.8-3.1)$ and females as 3.09 (1.0-9.5), $23.2 \%$ of target groups in high TAC's and their risk estimate for males as 1.8 (0.69-4.9) and 1.6 (0.75-3.2) for females, $24.1 \%$ of the study respondents with high LDL-C and their risk estimate for males as $1.6(0.8-3.2)$ and females 3.3 (1.1-10.0) and 51.4\% of low HDL-C respondents whose OR for males 0.3 (0.11-0.71) and females 1.0 $(0.50-1.9)$ were in the prevalence of prediabetes.

A logistic regression model was used to examine the association of all possible variables with prediabetes is presented in Table 4. In the present study, variables including sex, age, occupation, income, drinking alcohol, BMI, WHtR, BP, LDL-C and HDL-C had a positive correlation in prediabetes of the target population.

Table 4. Binary logistic regression model to examine the association of prediabetes with other variables $(\mathrm{N}=364)$.

\begin{tabular}{|c|c|c|c|c|c|}
\hline Variable & Category & $\operatorname{Exp}(\beta)$ & $(95 \% \mathrm{CI})$ & df & P-Value \\
\hline Sex & Male & 1 & & 1 & \\
\hline \multirow[t]{4}{*}{ Age } & $\begin{array}{l}\text { Female } \\
35-39 \\
40-44\end{array}$ & $\begin{array}{l}2.2 \\
1 \\
3.2\end{array}$ & $\begin{array}{l}(1.1-4.2) \\
(0.7-14.1)\end{array}$ & 4 & $\begin{array}{l}0.03 \\
0.05 \\
0.11\end{array}$ \\
\hline & $45-49$ & 5.9 & $(1.4-26.2)$ & & 0.02 \\
\hline & $50-54$ & 8.1 & $(1.6-40.1)$ & & 0.01 \\
\hline & $55-59$ & 3.6 & $(0.6-22.3)$ & & 0.12 \\
\hline \multirow[t]{4}{*}{ Occupation } & Academic Instructor & 1 & & 3 & 0.02 \\
\hline & Skilled worker & 8.2 & $(2.3-29.3)$ & & 0.001 \\
\hline & Office Personal & 5.8 & $(1.8-19.3)$ & & 0.004 \\
\hline & Administration worker & 8.3 & $(2.7-25.1)$ & & 0.001 \\
\hline \multirow[t]{3}{*}{ Income } & Low & 1 & & 2 & 0.007 \\
\hline & Medium & 0.51 & $(0.24-1.0)$ & & 0.05 \\
\hline & High & 2.8 & $(1.12-7.5)$ & & 0.04 \\
\hline Drinking alcohol & No & $\begin{array}{l}1 \\
0.59\end{array}$ & $(0.29-1.1)$ & 1 & 0.05 \\
\hline \multirow[t]{3}{*}{ BMI } & Normal weight (18.5 - 24.9) & 1 & & 2 & 0.001 \\
\hline & Overweight $(25.0-29.9)$ & 3.2 & $(1.4-7.2)$ & & 0.005 \\
\hline & Obese ( $\geq 30$ and above) & 9.6 & $(2.8-32.7)$ & & 0.001 \\
\hline \multirow[t]{2}{*}{ Waist to Height ratio } & No risk & 1 & & 1 & \\
\hline & Risk & 2.6 & $(1.2-5.2)$ & & 0.01 \\
\hline \multirow[t]{2}{*}{ Blood pressure } & No & 1 & & 1 & \\
\hline & Yes & 2.5 & $(1.3-5.2)$ & & 0.01 \\
\hline \multirow[t]{2}{*}{$\mathrm{LDL}-\mathrm{C}$} & No risk & 1 & & 1 & \\
\hline & Risk & 2.4 & $(1.2-5.1)$ & & 0.02 \\
\hline \multirow[t]{2}{*}{$\mathrm{HDL}-\mathrm{C}$} & No risk & 1 & & 1 & \\
\hline & Risk & 0.97 & $(0.4-1.5)$ & & 0.05 \\
\hline
\end{tabular}




\section{Discussion}

We observed the total prevalence of prediabetes as $20.3 \%$ with normal glucose tolerance (NGT), impaired fasting glucose (IFG) and/or impaired glucose tolerance (IGT) as $79.7 \%, 8.0 \%, 6.8 \%$ and $5.5 \%$, respectively. Our findings are consistent with the prevalence observed in other regional studies as $12 \%$ in rural Kolabida town, North West Ethiopia (33), $11.5 \%$ in South East Amhara region (34), 29.6\% in Gondar (35), 24.4\% in HIV-1 adults (36) and $26.7 \%$ in TB patients (37) of Addis Ababa. In the global level $6.0 \%$ of prevalence in Nigeria (38), $26.5 \%$ in rural Uganda (39), $28.52 \%$ in China(40), IFG (7.1\%) and IGT (2.9\%) in Ireland (41) and 6\% of prevalence in Tanzania (42).

The present study showed significance in alcohol consumption $\left(\chi^{2}=4.657: p<0.01\right)$, unhealthy eating habits $\left(\chi^{2}=1.253: \mathrm{p}<0.05\right)$ and physical inactivity $\left(\chi^{2}=1.964: \mathrm{p}<0.04\right)$ in both male and female respondents. Alcohol consumption increases the concentration of gamma glutamyltransferase (GGT) in the liver (43) which gradually increases the odd's ratio for IFG (44). The odds ratio of unhealthy eating habits and physical inactivity was higher in females compared to males. This might be due to the fact that females are more sedentary in their lifestyle because of cultural feeding practice in the community, improper schedule in food consumption, facing socio-economic problems, frequent pregnancy, resolving family issues and severe stress in a working environment made the females at higher risk for prediabetes than males. The result of our study was supported by other findings stating that unhealthy eating habits and physical inactivity levels are higher in females compared to males (45).

Obesity is a powerful predictor of the development of T2DM which is positively influenced by physical inactivity and excess intake of macronutrient in the diet. Our findings showed a higher prevalence of obesity (BMI: $\chi^{2}=7.590$, WC: $\chi^{2}=5.652$, WHR: $\chi^{2}=$ 9.183 and WHtR: 6.747) in male and female respondents. The distribution of body fat is an important determinant of risk because it accurately measures the abdominal obesity which is observed by higher waist circumference (OR: 2.5 ) in males than in females (OR: 1.2). Our findings are supported by other investigations of higher obesity in females (46) and office workers $(47,48)$.

A significant association was observed in elevated blood pressure $\left(\chi^{2}=27.671\right)$ and total lipid profile (TC: $\chi^{2}=4.455: \mathrm{p}<0.01$, TG: $\chi^{2}=3.472: \mathrm{p}<0.02$, HDL-C: $\chi^{2}=2.457: \mathrm{p}<0.03$ and LDL- C: $\chi^{2}=5.131$ : $\mathrm{p}<0.008)$ toward prediabetes in the male and female target groups. The results are in accordance with studies suggesting that high BMI, hypertension and elevated triglycerides were significantly associated with increased risk of prediabetes (40).

According to ADA expert panel, $70 \%$ of individuals with prediabetes will progress to diabetes (49). A logistic regression model was used to predict the potential effect of risk factors in prediabetes. Variables including sex, age, occupation, income, alcohol, BMI, WHR, BP, LDL-C and HDL-C are strongly associated with prediabetes. The identified risk factors are almost observed in several research works (50).

The present study demonstrated the cluster effect of elevated risk factors and its significance in prediabetes. So it is important to maintain the normal BP, blood glucose, BMI and regular physical exercise to avoid prediabetes. These modifiable risk factors are the core targets in different intervention programs conducted all over the world. They support the change in lifestyle habits by losing excess body weight, regular physical exercise and dietary management could reduce the onset of T2DM. This study may be considered as one of the pre-trial in screening the people to prevent the progression of T2DM and to promote the healthy lifestyle in the near future in Oromia Region.

\section{Conclusion}

This study presented a higher prevalence of prediabetes and the effect of associated risk factors in the target population. We observed a higher prevalence compared with earlier research investigations because of urbanization, institutional study and the age of sample population which was $\geq$ 35 years. In the present scenario, it is highly recommended to conduct a set of intervention programs in the form of counseling to the individual clients after successive screening for prediabetes. The core theme of health education should focus on modifying the risk factors such as reducing obesity, maintaining the routine exercise and proper intake of healthy diet. This strategy can effectively manage the prediabetes and control a huge number of people from the risk of T2DM.

\section{Acknowledgements}

This study is part of the research portfolio of the College of Medicine and Health Sciences and the authors gratefully acknowledge the financial support provided by the Research, Consultancy and Community Service Office (RCCS) of Ambo University, Ethiopia.

\section{Author Contributions}

RV designed the study, wrote the protocol, performed the interpretation of data and wrote the first draft of 
the manuscript. GT and TA managed the acquisition of data and performed the analysis. RV performed a critical revision of the manuscript and managed the literature searches. BA and LK performed the administrative, technical and material support. All the authors provided their input throughout the study and approved the final manuscript.

\section{Competing interest}

All the authors state that there is no conflict of interest in this research work.

\section{References}

1. Sarah W, Anders G, Sicree R, King H. Global prevalence of diabetes, epidemiology/health services/psychosocial research. Diabetes Care. 2004; 27(5): 1047-53. PMID: 15111519.

2. McNeely MJ, Boyko EJ, Leonetti DL, Kahn SE, Fujimoto WY. Comparison of a clinical model, the oral glucose tolerance test, and fasting glucose for prediction of type 2 diabetes risk in Japanese Americans. Diabetes Care. 2003; 26 (3): 758-63. PMID: 12610034.

3. Hjellvik V, Sakshaug $\mathrm{S}$, Strom H. Body mass index, triglycerides, glucose, and blood pressure as predictors of Type 2 diabetes in a middle-aged Norwegian cohort of men and women. Clin Epidemiol. 2012; 4: 213-24. PMID: 22936857.

4. American diabetic association. Classification and diagnosis of diabetes. Diabetes Care. 2015; 38 Suppl: S8-S16. PMID: 25537714 .

5. American diabetic association. Diagnosis and classification of diabetes mellitus. Diabetes Care. 2010; 33 Suppl 1: S62-S69. PMID: 20042775 .

6. Forouhi NG, Luan J, Hennings S, Wareham NJ. Incidence of type-2 diabetes in England and its association with baseline impaired fasting glucose: The early study 1990-2000. Diabetes Med. 2007; 24(2): 200-7. PMID: 17257284

7. Nathan DM, Davidson MB, De - Fronzo RA, Heine RJ, Henry RR, Pratley R, Zinman B. Impaired fasting glucose and impaired glucose tolerance: implications for care. Diabetes Care. 2007; 30 (3): 753-9. PMID: 17327355.

8. Oguoma VM, Nwose EU, Ulasi II, Akintunde AA, Chukwukelu EE, Bwititi PT. Cardiovascular disease risk factors in a Nigerian population with impaired fasting blood glucose level and diabetes mellitus. BMC Public Health. 2017; 17(1): 36. PMID: 28061844.

9. Nwose EU, Oguoma VM, Bwititi PT, Richards RS. Metabolic syndrome and prediabetes in Ndokwa community of Nigeria: Preliminary study. N Am J Med Sci. 2015; 7 (2): 53-8. PMID: 25789249.

10. Balde NM, Diallo I, Balde MD, Barry IS, Kaba L, Diallo MM Diabetes and impaired fasting glucose in rural and urban populations in Futa Jallon (Guinea): Prevalence and associated risk factors. Diabetes Metab. 2007; 33: 114-20. PMID: 17363316.

11. Rathmann W, Kowall B, Heier M, Herder C, Holle R, Thorand B. Prediction models for incident Type 2 diabetes mellitus in the older population: KORA S4/F4 cohort study. Diabet Med. 2010; 27: 1116-23. PMID: 20854378.
12. Wilson PW, Meigs JB, Sullivan L, Fox CS, Nathan DM, D'Agostino RB. Prediction of incident diabetes mellitus in middleaged adults: the Framingham offspring study: Arch Intern Med. 2007; 167(10): 1068-74. PMID: 17533210.

13. WHO. Use of glycated haemoglobin (HbA1C) in diagnosis of diabetes mellitus. 2011; Report of a WHO Consultation, Geneva.

14. Ziemer DC, Kolm P, Weintraub WS, Vaccarino V, Rhee MK, Jennifer GT. Glucose-independent, black-white differences in haemoglobin A1C levels: A cross-sectional analysis of 2 studies. Ann Intern Med. 2010; 152 (12): 770 -7. PMID: 20547905.

15. Selvin E, Steffes MW, Ballantyne CM, Hoogeveen RC, Coresh J, Brancati FL. Racial differences in glycaemic markers: a crosssectional analysis of community based data. Ann Intern Med. 2011; 154 (5): 303-9. PMID: 21357907.

16. Tuomilehto J, Lindstrom J, Eriksson JG, Valle TT, Hamalainen $\mathrm{H}$, Illane-Parikka P. Finnish diabetes prevention study group. Prevention of type 2 diabetes mellitus by changes in lifestyle among subjects with impaired glucose tolerance. N Engl J Med. 2001; 344(18): 1343-50. PMID: 11333990.

17. Ramachandran A, Snehalatha C, Mary S, Mukesh B, Bhaskar $\mathrm{AD}$, Vijay $\mathrm{V}$. The Indian diabetes prevention programme shows that lifestyle modification and metformin prevent type 2 diabetes in Asian Indian subjects with impaired glucose tolerance (IDPP-1). Diabetologia. 2006; 49 (2): 289-97. PMID: 16391903.

18. Knowler WC, Barrett-Connor E, Fowler SE, Hamman RF, Lachin JM, Walker EA, Nathan DM. Diabetes prevention program research group. Reduction in the incidence of type 2 diabetes with lifestyle intervention or metformin. N Engl J Med. 2002; 346(6): 393-403. PMID: 11832527.

19. Worku D. Patterns of diabetic complications at Jimma University specialized hospital, Southwest Ethiopia. Ethiop J Health Sci. 2010; 20 (1): 33-40

20. Megersa YC, Gebre MW, Birru SK, Goshu AR, Tesfaye DY. Prevalence of undiagnosed diabetes mellitus and its risk factors in selected institutions at Bishoftu town, East Shoa, Ethiopia. J Diabetes Metab. 2013; S12: 008.

21. Daniel WW. Biostatistics: A foundation for analysis in the health sciences. $7^{\text {th }}$ Edition, New York, John Wiley \& Sons, 1999

22. Carter C. Examination of prediabetes and diabetes perceptions and knowledge using focus groups. Clemson University, ProQuest Dissertations Publishing, 2008. p 530

23. Campbell Nerissa J. The measurement of physical activity and self-efficacy in adolescents: Prospects, problems, and future directions. 2012; Electronic Thesis and Dissertation Repository. Paper 599.

24. NHLBI, Obesity Education Initiative. The practical guide: Identification, evaluation and treatment of overweight and obesity in adults. National Institutes of Health (NIH) Publication Number 00 - 4084: 2000.

25. WHO. Waist circumference and waist to hip ratio report. Geneva, 2008; 1-39.

26. Ashwell, M Gunn, P and Gibson, S. Waist-to-height ratio is a better screening tool than waist circumference and BMI for adult cardiometabolic risk factors: systematic review and meta-analysis. Obes Rev. 2012; 13(3): 275-86. PMID: 22106927. 
27. Chobanian AV, Bakris GL, Black HR, Cushman WC, Green LA, Izzo JL. Seventh report of the joint national committee on prevention, detection, evaluation and treatment of high blood pressure. Hypertension. 2003; 42(6): 1206-52. PMID: 14656957.

28. Executive summary of the third report of the National Cholesterol Education Program (NCEP) expert panel on detection, evaluation, and treatment of high blood cholesterol in adults (Adult Treatment Panel III). JAMA. 2001; 285(19): 2486-97. PMID: 11368702.

29. NHANES. Oral glucose tolerance test procedures manual. CDC. $2007 ; 1$.

30. WHO. International diabetes foundation, definition and diagnosis of diabetes mellitus and intermediate hyperglycaemia. 2006; Report of a WHO/IDF Consultation, Geneva.

31. ECDCD. Report of the expert committee on the diagnosis and classification of diabetes mellitus. Diabetes Care. 2003; 26 (Supp11): S5-S20. DOI: 10.2337/diacare.26.2007.S5 .

32. Mohan V, Shanthirani S, Deepa R, Premalatha G, Sastry NG, Saroja R. Intra urban differences in the prevalence of the metabolic syndrome in Southern India - The Chennai Urban Population Study (CUPS). Diabet Med. 2001; 18(4): 280-7. PMID: 11437858.

33. Worede A, Alemu S, Gelaw AY and Abebe M. The prevalence of impaired fasting glucose and undiagnosed diabetes mellitus and associated risk factors among adults living in a rural Koladiba town, Northwest Ethiopia. BMC Res Notes, 2017; 10(1): 251 PMID: 28683811.

34. Workneh MH, Bjune GA, Yimer SA. Prevalence and associated factors of diabetes mellitus among tuberculosis patients in South-Eastern Amhara Region, Ethiopia: A cross-sectional study. PLoS One. 2016; 11(1): e0147621. PMID: 26808967.

35. Getachew A, Mekonnen S, Alemu S, Yusuf H. High magnitude of diabetes mellitus among active pulmonary tuberculosis patients in Ethiopia. British J Medicine Medical Res. 2014; 4: 862-72.

36. Hagos AG. Prevalence of in HIV-1 infected adults receiving antiretroviral therapy in Addis Ababa, Ethiopia. Int J Pharma Sci Res. 2015; 6(2): 440-3.

37. Damtew E, Ali I, Meressa D. Prevalence of diabetes mellitus among active pulmonary tuberculosis patients at St. Peter Specialized Hospital. Addis Ababa, Ethiopia. World J Med Sci. 2014; 11: 389-96.

38. Rasaki SO, Kasali FO, Biliaminu SA, Odeigah LO, Sunday AA, Sule AG, et al. Prevalence of diabetes and prediabetes in Oke-Ogun region of Oyo State, Nigeria. Cogent Med. 2017; 4: 1326211. DOI/10.1080/2331205X.2017.1326211.

39. Chiwanga FS, Njelekela MA, Diamond MB, Bajunirwe F, Guwatudde D, Nankya-Mutyoba J, et al. Urban and rural prevalence of diabetes and prediabetes and risk factors associated with diabetes in Tanzania and Uganda. Glob Health Action. 2016; 9: 31440. PMID: 27221531.
40. Ming Z, Hongbo L, Yanyan Y, Fuyan W, Yang X, Li M, et al. Prevalence of prediabetes and its associated risk factors in rural areas of Ningbo, China. Int J Environ Res Public Health. 2016; 13(8): 808. PMCID: PMC4997494.

41. Sinnott M, Kinsley BT, Jackson AD, Walsh C, O'Grady T, Nolan JJ, et al. Fasting plasma glucose as initial screening for diabetes and prediabetes in Irish adults: The diabetes mellitus and vascular health initiative (DMVhi). PLOS One. 2015; 10(4): e0122704. PMID: 25874867.

42. Khambalia A, Phongsavan P, Smith BJ, Keke K, Dan L, Fitzhardinge A, et al. Prevalence and risk factors of diabetes and impaired fasting glucose in Nauru. BMC Public Health. 2011; 11: 719. PMID: 21943388.

43. Sharpe PC. Biochemical detection and monitoring of alcohol abuse and abstinence. Ann Clin Biochem. 2001; 38(pt6): 652-4. PMID: 11732647

44. Kim DJ, Noh JH, Cho NH, et al. Serum $\gamma$-glutamyltransferase within its normal concentration range is related to the presence of diabetes and cardiovascular risk factors. Diabet Med. 2005; 22(9): 1134-40. PMID: 16108838.

45. Jali MV, Kambar S. Prevalence of diabetes among the family members of known diabetics. Int J Diab Dev Ctries. 2006; 26: 815 .

46. Solomon MA, Yemane B, Alemayehu W, Abebayehu A. Diabetes mellitus in North West Ethiopia: A community based study. BMC Public Health. 2014; 14: 97. PMID: 24479725.

47. Wilmot EG, Edwardson CL, Achana FA, Davies MJ, Gorely $\mathrm{T}$, Gray LJ, et al. Sedentary time in adults and the association with diabetes, cardiovascular disease and death: Systematic review and meta-analysis. Diabetologia. 2012; 55(11): 2895-905. PMID: 22890825

48. Agrawal P, Gupta K, Mishra V and Agrawal S. Effects of sedentary lifestyle and dietary habits on body mass index change among adult women in India: Findings from a follow-up study. Ecol Food Nutr. 2013; 52(5): 387-406. PMID: 23927045.

49. Tabak AG, Herder C, Rathmann W, Brunner EJ, Kivimaki M. Prediabetes: A high-risk state for diabetes development. Lancet. 2012; 379(9833): 2279-90. PMID: 22683128.

50. Mohammed AS, Kamlesh B, Yahya MF, Shirley V, Ahmed M, Samir A, Abdullah M. Prevalence of prediabetes and associated risk factors in an adult Omani population. Int J Diab Dev Ctries. 2011; 31: 166-74. 